\title{
Fecal pancreatic elastase-1 levels in older individuals without known gastrointestinal diseases or diabetes mellitus
}

\author{
Karl-Heinz Herzig ${ }^{1,2,3^{*}}$, Anna-Kaisa Purhonen ${ }^{1,2}$, Kati M Räsänen ${ }^{1}$, Joanna Idziak , Petri Juvonen ${ }^{4}$, Ryszard Phillps ${ }^{5}$, \\ Jaroslaw Walkowiak ${ }^{6}$
}

\begin{abstract}
Background: Structural changes occur in the pancreas as a part of the natural aging process. With aging, also the incidence of maldigestive symptoms and malnutrition increases, raising the possibility that these might be caused at least in part by inadequate pancreatic enzyme secretion due to degenerative processes and damage of the gland. Fecal elastase-1 is a good marker of pancreatic exocrine secretion. The aim of this study was to investigate the fecal elastase-1 levels among over 60 years old Finnish and Polish healthy individuals without any special diet, known gastrointestinal disease, surgery or diabetes mellitus.
\end{abstract}

Methods: A total of 159 patients participated in this cross-sectional study. 106 older individuals (aged 60-92 years) were recruited from outpatient clinics and elderly homes. They were divided to three age groups: 60-69 years old $(n=31) ; 70-79$ years old $(n=38)$ and over 80 years old $(n=37) .53$ young subjects ( 20 -28 years old) were investigated as controls. Inclusion criteria were age over 60 years, normal status and competence. Exclusion criteria were any special diet, diabetes mellitus, any known gastrointestinal disease or prior gastrointestinal surgery. Fecal elastase-1 concentration was measured from stool samples with an ELISA that uses two monoclonal antibodies against different epitopes of human elastase-1.

Results: Fecal elastase-1 concentrations correlated negatively with age (Pearson $r=-0,3531, P<0.001$ ) and were significantly lower among subjects over 70 years old compared to controls (controls vs. 70-79 years old and controls vs. over 80 years old, both $P<0.001$ ). Among the over 60 years old subjects, the fecal elastase-1 concentrations were below the cut off level of $200 \mu \mathrm{g} / \mathrm{g}$ in 23 of $106(21.7 \%)$ individuals [mean $112(86-138) \mu \mathrm{g} / \mathrm{g}$ ] indicating pancreatic exocrine insufficiency. Of those, 9 subjects had fecal elastase-1 level below $100 \mu \mathrm{g} / \mathrm{g}$ as a marker of severe pancreatic insufficiency.

Conclusion: In our study one fifth of healthy older individuals without any gastrointestinal disorder, surgery or diabetes mellitus suffer from pancreatic exocrine insufficiency and might benefit from enzyme supplementation therapy.

\section{Background}

The structural changes occurring in the pancreas as a part of the natural aging process include patchy fibrosis, lipomatosis, ductal epithelial hyperplasia, ductal widening and intraluminal protein deposition which have been documented in postmortem studies [1-4]. With

\footnotetext{
* Correspondence: karl-heinz.herzig@oulu.fi

'Department of Biotechnology and Molecular Medicine, A.I. Virtanen Institute for Molecular Sciences, University of Eastern Finland, Kuopio, Finland Full list of author information is available at the end of the article
}

aging, also the incidence of maldigestive symptoms and malnutrition increases, raising the possibility that these might be caused at least in part by inadequate pancreatic enzyme secretion due to degenerative processes and damage of the gland.

Only very few previous studies have addressed the effect of aging on pancreatic exocrine secretion capacity and those have reported inconsistent results. Gullo et al did not find any decrease in exocrine pancreatic function measured by pancreolauryl test in older people (aged 66 to 88

\section{Biomed Central}

(c) 2011 Herzig et al; licensee BioMed Central Ltd. This is an Open Access article distributed under the terms of the Creative Commons Attribution License (http://creativecommons.org/licenses/by/2.0), which permits unrestricted use, distribution, and reproduction in any medium, provided the original work is properly cited. 
years, mean age 78) [5] nor when investigated by fecal elastase- 1 tests in over 90 years old subjects [6]. In contrast, other studies demonstrated that lipase, chymotrypsin and bicarbonate secretion after secretin and cholecystokinin (CCK) stimulation decreases with age [7] and approximately $40 \%$ reduction in enzyme output was observed in older people under secretin and cerulein stimulation as compared with the younger subjects [8]. In an older population with a mean age of 58.7 years significantly lower secretion rates for bicarbonate following secretin and for the enzymes lipase and amylase following pancreozymin administration compared to a healthy young population with a mean age of 31.8 years have been reported [9]. A large-scale, population based, cohort study evaluated pancreatic exocrine secretion in 50 to 75 years old subjects [10]. In this cohort $11.5 \%$ showed signs of exocrine pancreatic insufficiency (elastase level $<200 \mu \mathrm{g} / \mathrm{g}$ stool) and $5.1 \%$ severe insufficiency (elastase level $<100 \mu \mathrm{g} / \mathrm{g}$ stool). $11.4 \%$ of the study population had a history of diabetes mellitus [10]. These studies suggest that pancreatic enzyme secretion may be reduced even in normal, healthy older people with no gastrointestinal diseases due to atrophy, fibrosis, sclerosis and lipomatosis of the organ.

Direct tests like the secretin-CCK or secretin-caerulein test have the highest sensitivity and specificity for the detection of exocrine pancreatic insufficiency, and they remain the gold standard for testing pancreatic exocrine function but they have various practical disadvantages being time consuming, invasive and expensive. Since pancreatic elastase- 1 is very stable during intestinal transit and is enriched five- to six fold in feces, it can be used in the assessment of the pancreatic exocrine secretory capacity $[11,12]$. Measuring fecal elastase- 1 concentration correlates moderately with direct tests [13] and has several advantages being non-invasive, inexpensive and allowing sample storage in room temperature up to five days. Many comparative studies support the value of fecal elastase- 1 test in the assessment of the pancreatic secretion capability. In addition, being species specific enzyme, human elastase-1 can be differentiated from the porcine elastase present in enzyme supplements.

The aim of our study was to evaluate the pancreatic exocrine secretion in older people with no known gastrointestinal disease, surgery or diabetes mellitus with a simple fecal elastase- 1 test to estimate the possible need for exogenous pancreatic enzyme replacement therapy in the older population.

\section{Methods}

\section{Subjects}

The study subjects were competent healthy individuals who were recruited from local elderly homes and health care centers from Eastern Finland and the ophthalmology outpatient clinic at the Department of Ophthalmology,
District Hospital, Poznan, Poland. The subjects signed an informed consent and the study was accepted by the ethical committee of Hospital district of Northern Savo, Kuopio, Finland and the ethical committee of Poznan University of Medical Sciences, Poland. All procedures complied with the Helsinki Declaration.

The inclusion criteria were over 60 years of age, normal status and competence. Exclusion criteria were any special diet, alcohol abusers, diabetes mellitus, any known gastrointestinal disease or prior gastrointestinal surgery. None of the subjects had been diagnosed with exocrine pancreatic insufficiency or had been treated with pancreatic enzymes before the study.

A total of 159 subjects participated in the study. Older individuals (total $\mathrm{n}=106$ ) were divided into three age groups i) 60-69 years old $(\mathrm{n}=31)$, ii) 70-79 years old $(\mathrm{n}=38)$, and iii) over 80 years old $(\mathrm{n}=37) .53$ young controls (age 20-28 years) served as the control group. The same selection criteria were applied to controls as well as to older subjects.

The fecal elastase- 1 was measured from $1 \mathrm{~g}$ of stool by an enzyme-linked immunosorbent assay $\left(\mathrm{ScheBo}^{\circledR} \mathrm{Tech}\right.$, Giessen, Germany). The test uses two monoclonal antibodies against different epitopes of human elastase-1. The intra- and inter-assay variations were $5.8 \%$ and $7.7 \%$, respectively. Each sample was measured in duplicates. To minimize the intra-individual variation, the measurement was repeated from three stool samples from each subject and the average of the three samples was used for calculation of the results. The cut-off level for pancreatic insufficiency is elastase- 1 concentration below $200 \mu \mathrm{g} / \mathrm{g}$ stool and for severe pancreatic insufficiency below $100 \mu \mathrm{g} / \mathrm{g}$ stool.

\section{Statistical analysis}

Normal distribution of the data was tested by Kolmogorov-Smirnov test. To compare the elastase- 1 levels between the groups, one-way ANOVA with Tukey's multiple comparison test as post test was used. $P<0.05$ was considered statistically significant. Correlation was tested by Pearson test. GraphPad Prism was used for statistical analysis (GraphPad Software Inc., San Diego, CA).

\section{Results}

Fecal elastase-1 concentration was (means and 95\% confidence intervals are given) $570(518-621) \mu \mathrm{g} / \mathrm{g}$ in controls, 458 (358-558) $\mu \mathrm{g} / \mathrm{g}$ in 60-69 years old, 375 (289461) $\mu \mathrm{g} / \mathrm{g}$ in 70-79 years old and 381 (321-442) $\mu \mathrm{g} / \mathrm{g}$ in over 80 years old subjects (Figure 1 ). The fecal elastase1 concentration was significantly lower in individuals over 70 years old compared to controls (controls vs. 7079 years and controls vs. over 80 years, both $P<0.001$ ). The difference between controls and 60-69 years old and the differences between the older age groups were 


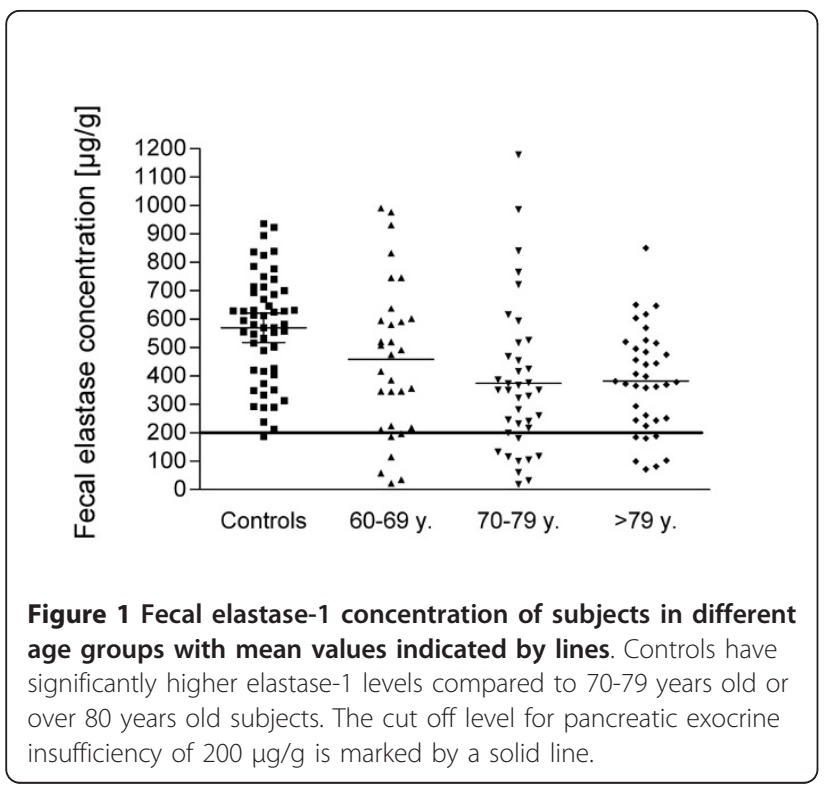

not statistically significant $(P>0.05)$. Fecal elastase- 1 concentration correlated negatively with age (Pearson $\mathrm{r}$ $=-0,3531, P<0.001$, Figure 2). Among the subjects over 60 years old, the fecal elastase- 1 concentration was below the cut off level of $200 \mu \mathrm{g} / \mathrm{g}$ in 23 of 106 (21.7\%) individuals [mean $112(86-138) \mu \mathrm{g} / \mathrm{g}$ ] indicating pancreatic exocrine insufficiency. 9 subjects had fecal elastase-1 level below $100 \mu \mathrm{g} / \mathrm{g}$ indicating severe pancreatic insufficiency. In the control group, one subject had an elastase-1 level below $200 \mu \mathrm{g} / \mathrm{g}$.

\section{Discussion}

In our investigation we found that $21.7 \%$ of subjects aged over 60 years without any known gastrointestinal diseases, gastrointestinal surgery or diabetes mellitus

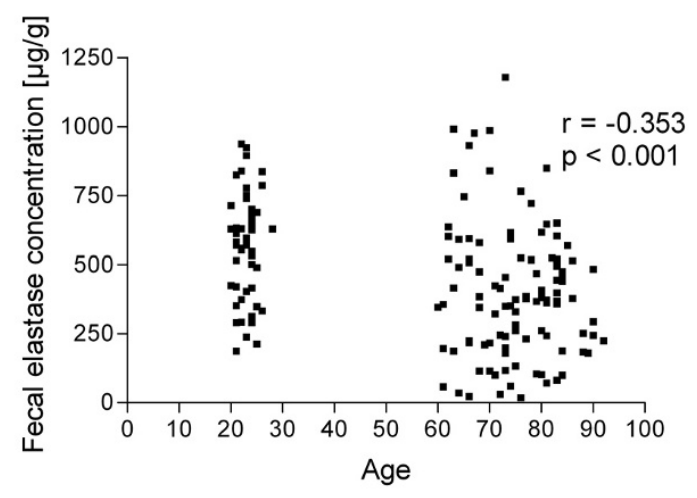

Figure 2 Fecal elastase-1 level correlates negatively with age. Pearson correlation $r=-0.353, P<0.001$. had fecal elastase-1 levels below $200 \mu \mathrm{g} / \mathrm{g}$ indicating pancreatic exocrine insufficiency. Reduction in exocrine secretion capacity leads to maldigestion of nutrients which might manifest as clinical symptoms like malnutrition, steatorrhoea, diarrhea, abdominal pain and weight loss [14]. In addition, as the cause of abdominal pain remains unclear in about $30 \%$ of the cases, pancreatic insufficiency should be considered as a possible etiology in these situations. Our results are comparable with other studies. Rothenbacher and others included also diabetics in their large population based study and found exocrine insufficiency (moderate or severe) in $22.7 \%$ and $19 \%$ of $65-69$ years and 70-75 years old subjects, respectively [10]. Another study reported elastase- 1 levels below $200 \mu \mathrm{g} / \mathrm{g}$ in $18.1 \%$ of the nondiabetic control subjects (mean age 58 years, range 22-80 years) [15]. In contrast, Gullo et al found that only one of 68 subjects over 90 years old and none in their control group (mean age 52 years, range $21-81$ years) had low fecal elastase-1 levels [6] and there was no correlation between fecal elastase- 1 and age. The discrepancy might be explained by tight selection criteria applied by Gullo and coworkers as their inclusion criteria included normal nutritional status and lifetime absence of important diseases, including digestive diseases, diabetes mellitus and alcohol abuse, suggested weight for height and normal biochemical examinations of several parameters possibly leading to exclusion of the cases with pancreatic insufficiency.

Measuring fecal elastase-1 level is the most appropriate indirect test to evaluate pancreatic exocrine function currently available at the clinics. The sensitivity of fecal elastase-1 measurement in detecting severe exocrine insufficiency is excellent $(100 \%$ in $[13,16,17]$ and $82 \%$ in [18]). In contrast, its sensitivity in mild pancreatic insufficiency in different studies has been reported to be ranging from 16,7 to $65 \%$ [13,16-20]. Some of the studies have been criticized for their small sample size or for underestimation of pancreatic insufficiency. However, considering the modest sensitivity of the test in detecting mild exocrine insufficiency, it should be noted that the actual prevalence of mild reduction in exocrine secretion capacity among older people is expected to be even higher than indicated by fecal elastase- 1 measurements. It is well known that the incidence of disturbances in the endocrine pancreatic function increases with age [21] yet the deterioration of the exocrine gland has gained much less attention. Interestingly, several studies have reported higher prevalence of impaired exocrine secretion capacity among diabetic patients than in nondiabetic controls [15,22-24] although the association has not been confirmed by all [10]. Different theories have been proposed why diabetes could impair exocrine secretion including atrophy of the exocrine 
tissue due to lack of trophic insulin, fibrosis as a result of angiopathy, impaired exocrine regulation due to neuropathy or vice versa suggesting that primary exocrine disease might cause diabetes mellitus [15]. As the pathophysiology of these events remains unknown, morphological studies support the connection between exocrine and endocrine disease since changes of the pancreas were observed among diabetics, among those with exocrine insufficiency and increasingly so in those patients with both disorders [25]. In addition to other pathophysiological mechanisms, the natural process of aging and degeneration could affect the endocrine as well as the exocrine part.

In our study, we evaluated fecal elastase- 1 levels in patients without known diabetes mellitus. The total prevalence of diabetes is between 10-20\% among 60-79 year old people and approximately half of these cases are undiagnosed [21]. Thus it is likely that our study included also some subjects with undiagnosed diabetes since we did not screen them by laboratory tests. The most common causes of exocrine pancreatic insufficiency are chronic pancreatitis and pancreatic surgery followed by other diseases like cystic fibrosis, acute necrotizing pancreatitis, Shwachman Diamond syndrome, celiac disease, irritable bowel syndrome and inflammatory bowel disease [26-29]. Patients with any gastrointestinal surgery or known gastrointestinal disease were excluded from our study but besides the impact of aging, also underlying undiagnosed diseases remain as possible etiological factors for reduced fecal elastase-1 levels. Nevertheless, our study suggests that among the apparently healthy older subjects without any known gastrointestinal disease there is a considerable portion of subjects who might benefit from pancreatic enzyme supplementation therapy. The decline of fecal elastase-1 level below the cut off level $200 \mu \mathrm{g} / \mathrm{g}$ may indicate already atrophy and degeneration of the gland. However, no correlation was found between fecal elastase- 1 levels and clinical symptoms of abdominal discomfort [15]. Clinically relevant maldigestion may occur earlier than the appearance of overt symptoms [30]. According to present recommendation, every patient with exocrine pancreatic insufficiency should be treated with pancreatic enzyme replacement therapy regardless of the amount of steatorrhoea, maldigestion or clinical symptoms [31].

\section{Conclusions}

Among older individuals without any known gastrointestinal disease, surgery or diabetes mellitus, one fifth of the individuals had abnormal fecal elastase- 1 levels indicating pancreatic exocrine insufficiency. In the general unselected population with a high incidence of diabetes mellitus, malabsorption syndromes and abdominal surgery the incidence might be even higher. It is important to increase the awareness of these problems in this population group among general physicians since for these patients, careful clinical examination and possibly pancreatic enzyme replacement therapy are warranted.

\section{Acknowledgements}

We thank Riitta Kauppinen for excellent technical assistance. Algol Oy, Helsinki, Finland kindly provided the ELISA kits for the elastase-1 measurements. The sponsor had no involvement in design, subject recruitment, data collections, analysis, or preparation of manuscript.

\section{Author details}

${ }^{1}$ Department of Biotechnology and Molecular Medicine, A.I. Virtanen Institute for Molecular Sciences, University of Eastern Finland, Kuopio, Finland. ${ }^{2}$ Institute of Biomedicine, Department of Physiology, University of Oulu, Oulu, Finland. ${ }^{3}$ Biocenter Oulu, University of Oulu, Oulu, Finland.

${ }^{4}$ Department of Surgery, Kuopio University Hospital, Kuopio, Finland.

${ }^{5}$ Department of Ophthalmology, District Hospital, Poznan, Poland. ${ }^{6}$. Chair of Pediatrics, Department of Gastroenterology \& Metabolism, Poznan University of Medical Sciences, Poznan, Poland.

\section{Authors' contributions}

$\mathrm{KHH}, \mathrm{AKP}$ and JW: study concept and design, acquisition of subjects, interpretation of data, preparation of manuscript. KR, J: analysis of samples, interpretation of data, manuscript preparation. KR, PJ, RP: acquisition of subjects, manuscript preparation. All authors read and approved the final manuscript.

\section{Competing interests}

The authors declare that they have no competing interests.

Received: 23 July 2010 Accepted: 25 January 2011

Published: 25 January 2011

\section{References}

1. Detlefsen S, Sipos B, Feyerabend B, Kloppel G: Pancreatic fibrosis associated with age and ductal papillary hyperplasia. Virchows Arch 2005, 447:800-805.

2. Pitchumoni CS, Glasser M, Saran RM, Panchacharam P, Thelmo W: Pancreatic fibrosis in chronic alcoholics and nonalcoholics without clinical pancreatitis. Am J Gastroentero/ 1984, 79:382-388.

3. Schmitz-Moormann P, Hein J: Changes of the pancreatic duct system associated with aging: their relations to parenchyma (author's transl). Virchows Arch A Pathol Anat Histol 1976, 371:145-152.

4. Stamm BH: Incidence and diagnostic significance of minor pathologic changes in the adult pancreas at autopsy: a systematic study of 112 autopsies in patients without known pancreatic disease. Hum Pathol 1984, 15:677-683.

5. Gullo L, Ventrucci M, Naldoni P, Pezzilli R: Aging and exocrine pancreatic function. J Am Geriatr Soc 1986, 34:790-792.

6. Gullo L, Simoni P, Migliori M, Lucrezio L, Bassi M, Frau F, Costa PL, Nestico V: A study of pancreatic function among subjects over ninety years of age. Pancreatology 2009, 9:240-244.

7. Laugier R, Bernard JP, Berthezene P, Dupuy P: Changes in pancreatic exocrine secretion with age: pancreatic exocrine secretion does decrease in the elderly. Digestion 1991, 50:202-211.

8. Vellas B, Balas D, Moreau J, Bouisson M, Senegas-Balas F, Guidet M, Ribet A: Exocrine pancreatic secretion in the elderly. Int J Pancreatol 1988, 3:497-502

9. Mossner J, Pusch HJ, Koch W: Exocrine pancreas function - does it change with age? (author's transl). Aktuelle Gerontol 1982, 12:40-43.

10. Rothenbacher D, Low M, Hardt PD, Klor HU, Ziegler $\mathrm{H}$, Brenner $\mathrm{H}$ : Prevalence and determinants of exocrine pancreatic insufficiency among older adults: results of a population based study. Scand J Gastroenterol 2005, 40:697-704.

11. Walkowiak J, Cichy WK, Herzig KH: Comparison of fecal elastase-1 determination with the secretin-cholecystokinin test in patients with cystic fibrosis. Scand J Gastroenterol 1999, 34:202-207.

12. Walkowiak J, Nousia-Arvanitakis S, Agguridaki C, Fotoulaki M, Strzykala K, Balassopoulou A, Witt M, Herzig KH: Longitudinal follow-up of exocrine 
pancreatic function in pancreatic sufficient cystic fibrosis patients using the fecal elastase-1 test. J Pediatr Gastroenterol Nutr 2003, 36:474-478.

13. Luth S, Teyssen S, Forssmann K, Kolbel C, Krummenauer F, Singer MV: Fecal elastase-1 determination: 'gold standard' of indirect pancreatic function tests? Scand J Gastroenterol 2001, 36:1092-1099.

14. Talley NJ, O'Keefe EA, Zinsmeister AR, Melton LJ: Prevalence of gastrointestinal symptoms in the elderly: a population-based study. Gastroenterology 1992, 102:895-901.

15. Hardt PD, Krauss A, Bretz L, Porsch-Ozcurumez M, Schnell-Kretschmer $H$, Maser E, Bretzel RG, Zekhorn T, Klor HU: Pancreatic exocrine function in patients with type 1 and type 2 diabetes mellitus. Acta Diabetol 2000, 37:105-110.

16. Gullo L, Ventrucci M, Tomassetti P, Migliori M, Pezzilli R: Fecal elastase 1 determination in chronic pancreatitis. Dig Dis Sci 1999, 44:210-213.

17. Loser C, Mollgaard A, Folsch UR: Faecal elastase 1: a novel, highly sensitive, and specific tubeless pancreatic function test. Gut 1996 39:580-586.

18. Lankisch PG, Schmidt I, Konig H, Lehnick D, Knollmann R, Lohr M, Liebe S: Faecal elastase 1: not helpful in diagnosing chronic pancreatitis associated with mild to moderate exocrine pancreatic insufficiency. Gut 1998, 42:551-554.

19. Naruse $S$, Ishiguro $H, K o$ SB, Yoshikawa $T$, Yamamoto $T$, Yamamoto $A$, Futakuchi S, Goto H, Saito Y, Takahashi S: Fecal pancreatic elastase: a reproducible marker for severe exocrine pancreatic insufficiency. J Gastroenterol 2006, 41:901-908.

20. Glasbrenner B, Schon A, Klatt S, Beckh K, Adler G: Clinical evaluation of the faecal elastase test in the diagnosis and staging of chronic pancreatitis. Eur I Gastroenterol Hepatol 1996, 8:1117-1120.

21. DECODE Study Group: Age- and sex-specific prevalences of diabetes and impaired glucose regulation in 13 European cohorts. Diabetes Care 2003, 26:61-69.

22. Rathmann W, Haastert B, Icks A, Giani G, Hennings S, Mitchell J, Curran S, Wareham NJ: Low faecal elastase 1 concentrations in type 2 diabetes mellitus. Scand J Gastroenterol 2001, 36:1056-1061.

23. Icks A, Haastert B, Giani G, Rathmann W: Low fecal elastase-1 in type I diabetes mellitus. Z Gastroenterol 2001, 39:823-830.

24. Hardt PD, Hauenschild A, Nalop J, Marzeion AM, Jaeger C, Teichmann J, Bretzel RG, Hollenhorst M, Kloer HU, S2453112/S2453113 Study Group: High prevalence of exocrine pancreatic insufficiency in diabetes mellitus. A multicenter study screening fecal elastase 1 concentrations in 1,021 diabetic patients. Pancreatology 2003, 3:395-402.

25. Bilgin M, Balci NC, Momtahen AJ, Bilgin Y, Klor HU, Rau WS: MRI and MRCP findings of the pancreas in patients with diabetes mellitus: compared analysis with pancreatic exocrine function determined by fecal elastase 1. J Clin Gastroenterol 2009, 43:165-170.

26. Walkowiak J, Herzig KH: Fecal elastase-1 is decreased in villous atrophy regardless of the underlying disease. Eur J Clin Invest 2001, 31:425-430.

27. Walkowiak J, Krawczynski M, Herzig KH: Giardiasis aggravates malabsorption in cystic fibrosis. Scand J Gastroenterol 2004, 39:607-608.

28. Whitcomb DC, Lehman GA, Vasileva G, Malecka-Panas E, Gubergrits N, Shen Y, Sander-Struckmeier S, Caras S: Pancrelipase Delayed-Release Capsules (CREON) for Exocrine Pancreatic Insufficiency due to Chronic Pancreatitis or Pancreatic Surgery: A Double-Blind Randomized Trial. Am J Gastroenterol 2010, 105:2276-2286

29. Leeds JS, Hopper AD, Sidhu R, Simmonette A, Azadbakht N, Hoggard N, Morley S, Sanders DS: Some patients with irritable bowel syndrome may have exocrine pancreatic insufficiency. Clin Gastroenterol Hepatol 2010, 8:433-438.

30. Dumasy V, Delhaye M, Cotton F, Deviere J: Fat malabsorption screening in chronic pancreatitis. Am J Gastroenterol 2004, 99:1350-1354.

31. Sikkens EC, Cahen DL, Kuipers EJ, Bruno MJ: Pancreatic enzyme replacement therapy in chronic pancreatitis. Best Pract Res Clin Gastroenterol 2010, 24:337-347.

\section{Pre-publication history}

The pre-publication history for this paper can be accessed here: http://www.biomedcentral.com/1471-2318/11/4/prepub

doi:10.1186/1471-2318-11-4

Cite this article as: Herzig et al:: Fecal pancreatic elastase-1 levels in older individuals without known gastrointestinal diseases or diabetes mellitus. BMC Geriatrics 2011 11:4.

\section{Submit your next manuscript to BioMed Central and take full advantage of:}

- Convenient online submission

- Thorough peer review

- No space constraints or color figure charges

- Immediate publication on acceptance

- Inclusion in PubMed, CAS, Scopus and Google Scholar

- Research which is freely available for redistribution

Submit your manuscript at www.biomedcentral.com/submit
Biomed Central 